\title{
Measurement of chemically-available iron in foods by incubation with human gastric juice in vitro
}

\author{
BY SUSAN LOCK AND A. E. BENDER \\ Department of Food Science and Nutrition, Queen Elizabeth College, \\ University of London, Campden Hill, London W8 $7 \mathrm{AH}$ \\ (Received I3 August I979-Accepted I I January 1980)
}

1. The proportion of iron liberated from twenty foods was measured after incubation in vitro with human gastric juice.

2. Results with samples of gastric juice obtained from one subject on ten occasions and from sixteen subjects on a single occasion showed good agreement, the proportions of Fe liberated covering the entire range from zero for egg to $\mathrm{I} \cdot \mathrm{O}$ for wine.

3. Where there were small variations between the results obtained with different samples of gastric juice attempts were made to correlate these with peptic activity, various proteins and mucoproteins, $\mathrm{pH}$ and total and free acid; the only factors that varied with the proportions of Fe solubilized were the various measures of acidity.

4. The results correlated highly with those of Layrisse et al. (1969) for the in vivo absorption of Fe from similar foods, although the samples used were not the same.

5. The amounts of Fe solubilized when the foods were mixed with bran, oats or egg (known to reduce the in vivo absorption of $\mathrm{Fe}$ from foods) were less than calculated from the sum of each, with two exceptions.

6. The results obtained with human gastric juice differed from those obtained with in vitro methods previously reported, namely treatment with dilute hydrochloric acid and double incubation with pepsin plus $\mathrm{HCl}$ at $\mathrm{pH} 2 \cdot 5$ followed by adjustment to $\mathrm{pH} 7 \cdot 5$.

7. The amount of Fe solubilized from soya-bean flour by gastric juice was compared with that solubilized by pepsin plus $\mathrm{HCl}$; both systems were shown to be $\mathrm{pH}$ dependent but the amount of Fe liberated with pepsin$\mathrm{HCl}$ was much greater than that known to be absorbed by man in vivo.

8. It is suggested that incubation with human gastric juice may permit in vitro analyses of 'chemicallyavailable' $\mathrm{Fe}$ in foods and thus be of value in food composition tables in terms of ' $\mathrm{Fe}$ equivalents' even though the amounts absorbed in vivo are subsequently influenced by other ingredients of the diet and by the Fe status of the individual.

The problem of determining the proportion of iron that is absorbed from the diet, biologically available, is well recognized. Three distinct groups of factors are involved: (I) the chemical form of the $\mathrm{Fe}$ in the food, about which little is known, apart from haem-Fe in meat; (2) the presence in the intestine of other food components, such as fructose, ascorbic acid and cysteine which increase the amount of $\mathrm{Fe}$ absorbed, and oxalate, phosphate and phytate which reduce the amount absorbed; (3) the physiological status of the individual, such as the size of Fe stores and possibly the acidity of the gastric juice.

Consequently, it is not surprising to find that even carefully conducted experiments such as those of Layrisse \& Martinez-Torres (I971) carried out under similar conditions on identical foods show a wide range in Fe absorption. For example, the proportion of $\mathrm{Fe}$ absorbed from soya bean ranged from 0.002 to 0.422 in a group of twenty-eight individuals.

Attempts have been made in the past to measure chemical availability by determining the proportion of ionizable $\mathrm{Fe}$ in the ferrous state (believed to be biologically available) extracted in water (Kohler et al. 1936) and saline (Sanford, 1960). More recently the solubility of $\mathrm{Fe}$ in foods has been measured in pepsin and hydrochloric acid (Jacobs \& Greenman 1969) and in pepsin- $\mathrm{HCl}$ adjusted to $\mathrm{pH} 6-7$ (Mg-Mg-Thwin et al. 1975 ; Narasinga Rao \& Prabhavathi, 1978).

In the present work it was shown that incubation of a range of foods with human gastric juice liberated $\mathrm{Fe}$ in amounts similar to those generally regarded as biologically available. 


\section{METHODS \\ Preparation of food samples}

The foods were prepared in the form, raw or cooked, in which they would be eaten and if cooked, they were dried at $50^{\circ}$ before being ground to pass through a sieve (no. 30 ).

\begin{tabular}{|c|c|}
\hline Almonds, ground (Safeway Stores) & Untreated \\
\hline Wheat bran (Prewett's) & Untreated \\
\hline Cocoa powder (Rowntrees) & Untreated \\
\hline Curry powder (British Pepper \& Spice Co.) & Untreated \\
\hline Eggs & Boiled hard \\
\hline $\begin{array}{l}\text { Lentils, Lens esculenta, Lebanese (Safeway } \\
\text { Stores) }\end{array}$ & Boiled for $\mathrm{I} h$ in 10 vol. water \\
\hline Oats (Porage; Scotts) & Boiled for $5 \mathrm{~min}$ in 3 vol. water \\
\hline $\begin{array}{l}\text { Peas, Pisum sativum (Mushy Processed; } \\
\text { Batchelors) }\end{array}$ & Boiled for $5 \mathrm{~min}$ \\
\hline Soya-bean flour (defatted) & Boiled for $5 \mathrm{~min}$ in $10 \mathrm{vol}$. water \\
\hline $\begin{array}{l}\text { Spinach, Spinacea oleracea (canned puree; } \\
\text { Smedley) }\end{array}$ & Boiled for $5 \mathrm{~min}$ \\
\hline Watercress, Nasturtium officinale, fresh & Freeze-dried \\
\hline Wine (Tonic, without added iron; Sanatogen) & \\
\hline Black beans, Phaseolus vulgaris & $\begin{array}{l}\text { Soaked overnight and boiled for } 2 \mathrm{~h} \text { in } \\
\text { I0 vol. water }\end{array}$ \\
\hline Mackerel, Scomber scombrus & Grilled, dried, defatted with acetone \\
\hline Lettuce, Lactuca sativa, fresh & Freeze-dried \\
\hline Liver, ox & Fried for $10 \mathrm{~min}$ \\
\hline Maize flour & Boiled for $5 \mathrm{~min}$ in 5 vol. water \\
\hline Rice, white & Boiled for $20 \mathrm{~min}$ \\
\hline Veal muscle & Fried for $10 \mathrm{~min}$ \\
\hline Wheat (wholemeal flour) & Boiled for $5 \mathrm{~min}$ in 5 vol. water \\
\hline
\end{tabular}

\section{Estimation of total Fe}

Samples were ashed in a muffle furnace at $450^{\circ}$ for $\mathrm{I} 8 \mathrm{~h}$. At this temperature losses of $\mathrm{Fe}$ are negligible (Basson \& Böhmer, 1972). The ash was dissolved in $5 \mathrm{ml}$ warm concentrated $\mathrm{HCl}$ (artisar) and the solution and washings made up to $25 \mathrm{ml}$ with distilled water: final strength of acid $2 \mathrm{M}$.

Fe was determined by atomic absorption spectrophotometry (AAS) using Fe standards containing similar amounts of $\mathrm{HCl}$.

\section{Collection of gastric juices}

Subjects presented themselves for gastric juice collection after an overnight fast. A Ryles tube was passed into the stomach and the subject then swallowed $500 \mathrm{ml}$ distilled water. After 15-20 min the gastric contents were removed with the aid of a syringe and filtered through Whatman no. 4I filter paper into a plastic container. The volume of gastric juice collected varied from 50 to $500 \mathrm{ml}$ depending on gastric emptying time and the extent of discomfort of the subject.

\section{In vitro gastric digestion}

Duplicate $0.2 \mathrm{~g}$ portions of the foods were incubated in plastic centrifuge-tubes with $5 \mathrm{ml}$ gastric juice at $37^{\circ}$ for $\mathrm{I} \cdot 5 \mathrm{~h}$. The mixture was then centrifuged at $\mathrm{I} 8000 \mathrm{~g}$ to precipitate any 
ferric hydroxide that might have been present in suspension. The supernatant fraction was removed for determination of solubilized Fe by AAS.

\section{Analysis of gastric juice}

pH was measured using a Corning EEL $\mathrm{pH}$ meter. Free acid was determined by titration with $0 \cdot 1 \mathrm{M}$-sodium hydroxide using Topfers reagent, and total acid using phenolphthalein indicator. Peptic activity was assayed by measurement of the concentration of peptides released from haemoglobin substrate when incubated for a fixed time with gastric juice (Anson, 1938). One unit of activity is equivalent to the absorbance resulting from reaction of the reagent with $0.001 \mathrm{M}$-tyrosine.

Fe content was estimated using AAS.

Proteins and mucoproteins were determined by electrophoresis on polyacrylamide gel by a modification of the method of Davis et al. (1969). Samples of gastric juice were applied to polyacrylamide gels together with cytochrome $\mathrm{C}$ as a marker and the proteins and mucoproteins separated by sodium decyl sulphate electrophoresis.

The gels were stained with coomassie blue for proteins and with Schiffs reagent for mucoproteins. Known molecular weight markers together with cytochrome $\mathrm{C}$ were run on separate gels and thus the approximate molecular weights of the proteins and mucoproteins were calculated. The gels were scanned in a densitometer and the concentration of each protein and mucoprotein in the gastric juice calculated.

\section{Simulated gastric digestion}

Portions of $0.2 \mathrm{~g}$ raw soya-bean fiour were incubated at $37^{\circ}$ for $\mathrm{I} \cdot 5 \mathrm{~h}$ with a range of solutions of pepsin $(5 \mathrm{ml}, 5 \mathrm{~g} / \mathrm{l})$, adjusted with $\mathrm{HCl}$ at intervals of 0.2 units to $\mathrm{pH}$ values ranging from $I \cdot 4$ to $2 \cdot 8$. After centrifuging the amount of Fe solubilized was measured as described previously.

Statistical significance was examined by the Mann-Whitney test and correlations by Pearson's method.

\section{RESULTS AND DISCUSSION}

The Fe solubilized from the twelve foods by gastric juice collected from one female subject (age 27 years) on ten occasions is shown in Table I; the total Fe content of the foods is included in Table 2. The results expressed as the proportion of total Fe present ranged from zero for egg to nearly $\mathrm{I} \cdot \mathrm{O}$, complete liberation, from the sample of wine.

The amounts liberated bore no relation to the total amount of $\mathrm{Fe}$ present which ranged from $4 \mu \mathrm{g} / \mathrm{g}$ wine to $830 \mu \mathrm{g} / \mathrm{g}$ curry powder.

Since the composition of human gastric juice varies from sample to sample and, as shown in Table $\mathrm{I}$, the $\mathrm{pH}$, free and total acid, pepsin activity and Fe content differed in each of the ten samples the close agreement of the replicated results suggests that it was the intrinsic chemical properties of the $\mathrm{Fe}$ in the various foods that was being measured.

Table 2 shows the amounts of Fe solubilized from the same foods by gastric juice obtained from sixteen additional subjects (seven male, nine female, age range $19-38$ years). The mean values were similar to those shown in Table $r$ for the one female subject and the ranking order of the twelve foods was almost identical.

The results obtained with different samples of gastric juice showed a degree of variation. In order to ascertain the reason(s) for differences in Fe solubility, a range of gastric juice variables was measured. These were $\mathrm{pH}$ of gastric juice, free and total acid, pepsin activity, proteins and mucoproteins present (as revealed by gel electrophoresis), Fe content of gastric juice, sex and age of subject and the degree of Fe solubilization in each food. The 
Table I. The proportion of total iron solubilized from foods with gastric juice samples from subject no. I on ten occasions

\begin{tabular}{lll}
\multicolumn{1}{c}{ Food samples* } & Mean & \multicolumn{1}{c}{ sD } \\
Almonds & 0.200 & 0.034 \\
Bran & 0.237 & 0.030 \\
Cocoa powder & 0.067 & 0.019 \\
Curry powder & 0.020 & 0.007 \\
Eggs & 0.00 & 0.00 \\
Lentils & 0.013 & 0.009 \\
Oats & 0.038 & 0.015 \\
Peas & 0.061 & 0.041 \\
Soya-bean flour & 0.132 & 0.026 \\
Spinach & 0.308 & 0.013 \\
Watercress & 0.023 & 0.015 \\
Tonic wine & 0.971 & 0.037 \\
pH & 1.88 & 0.13 \\
Free acid & 14.3 & 5.2 \\
Total acid & 19.3 & 6.3 \\
Pepsin $\left(u n i t s / m l \times 10^{3}\right) \dagger$ & 1.16 & 0.19 \\
Fe $(\mu g / m l)$ & 0.037 & 0.047
\end{tabular}

* For details of samples and their preparation, see p. 414.

+ One unit of activity was defined as the absorbance resulting from $0.001 \mathrm{M}$-tyrosine under conditions of the assay.

Table 2. Total iron and proportion solubilized from foods with gastric juice samples from sixteen subjects

(Seven males, nine females, ages $19-39$ years)

\begin{tabular}{|c|c|c|c|c|}
\hline \multirow[b]{2}{*}{ Food sarrple* } & \multirow{2}{*}{$\begin{array}{c}\text { Total iron } \\
(\mu \mathrm{g} / \mathrm{g})\end{array}$} & \multicolumn{3}{|c|}{ Proportion solubilized } \\
\hline & & Mean & Range & so \\
\hline Almonds & $42 \cdot 5$ & 0.166 & $0.05-0.32$ & 0.062 \\
\hline Bran & $160 \cdot 3$ & 0.199 & $0.08-0.29$ & 0.051 \\
\hline Cocoa porvder & $177^{\circ} 0$ & 0.044 & $0.02-0.10$ & 0.021 \\
\hline Curry powder & $83 I \cdot 3$ & 0.015 & $0.01-0.03$ & 0.007 \\
\hline Eggs & $76 \cdot 3$ & 0.013 & $0.00-0.06$ & 0.018 \\
\hline Lentils & 87.5 & 0.025 & $0.00-0.13$ & 0.031 \\
\hline Oats & $61 \cdot 7$ & 0.028 & $0.00-0.05$ & 0.019 \\
\hline Peas & $64 \cdot 0$ & 0.099 & $0.04-0.28$ & 0.060 \\
\hline Soya-bean flour & $157^{\prime} 1$ & 0.167 & $0.12-0.27$ & 0.040 \\
\hline Spinach & $375^{\circ} 0$ & 0.321 & $0.27-0.45$ & 0.051 \\
\hline Watercress & $617 \cdot 5$ & 0.019 & $0.01-0.05$ & 0.011 \\
\hline Tonic wine & $4 \cdot 1$ & 0.985 & $0.90-1.04$ & 0.038 \\
\hline
\end{tabular}

* For details of samples and their preparation, see p. 414.

results were then analysed by partial correlation to see whether any pair of variables were related when the effects of the others had been eliminated. The only factors that were related to the amounts of Fe solubilized were the various measures of acidity.

The foods fell into two groups: ( 1 ) those in which the proportion of Fe solubilized increased with increasing acidity, i.e. bran $(r 0.64, P<0.05)$ cocoa powder $(r 0.64, P<0.0$ I $)$ and curry powder $(r 0.68, P<0.00 \mathrm{I})$; (2) those in which it decreased with increasing acidity, i.e. soya-bean flour $(r-0.57, P<0.05)$, lentils $(r-0.76, P<0.001), \operatorname{egg}(r-0.76, P<0.05)$ and peas $(r-0.66, P<0.00 \mathrm{I})$.

There were no differences between males and females for any of the variables measured; age correlated positively with $\mathrm{pH}(r 0.64 ; P<0.01)$ and hence negatively with free acid $(r-0.57, P=0.02)$ total acid $(r-0.57, P=0.02)$ and pepsin $(r-0.77, P<0.001)$. 
Table 3. Iron ( $\mu \mathrm{g})$ solubilized from foods with $5 \mathrm{ml}$ gastric juice $(\mathrm{pH} \mathrm{2 \cdot 2})$ with and without bran, oats and egg (total weight of food $0.2 \mathrm{~g}$ )

Treatment ...

Food alone $\overbrace{\text { Calculated Actual }}^{\text {Plus bran }} \overbrace{\text { Calculated Actual }}^{\text {Plus oats }} \overbrace{\text { Calculated Actual }}^{\text {Plus eggs }}$

Food sample*

Egg

Bran

Oats

Black beans

Fish

Lettuce

0.54

6.75

0.26

0.39

0.13

Liver

Maize flour

Rice

Soya-bean flour

Spinach

Veal muscle

Tonic wine $(2 \mathrm{ml})$

Wheat

$\begin{array}{cc}- & - \\ - & - \\ 3.75 & 2.21 \\ 3.44 & 0.52 \\ 4.09 & 2.08 \\ 6.57 & 6.51 \\ 3.44 & 1.82 \\ 3.88 & 1.70 \\ 4.91 & 1.83 \\ 7.67 & 9.11 \\ 3.57 & 1.17 \\ - & - \\ 3.57 & 3.38\end{array}$

$Z$
-
0.33
0.20
0.85
3.32
0.20
0.13
1.66
4.43
0.33
-
0.33

-
-
0.13
0.00
1.95
0.65
0.00
0.00
0.69
6.77
0.13
-
0.13

\begin{tabular}{|c|c|}
\hline- & - \\
\hline- & - \\
\hline- & - \\
\hline- & - \\
\hline 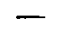 & - \\
\hline- & - \\
\hline & 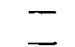 \\
\hline- & - \\
\hline $\mathrm{I} \cdot 80$ & 1.01 \\
\hline 4.57 & 3.29 \\
\hline & 0.00 \\
\hline $4 \cdot 37$ & $1 \cdot 12$ \\
\hline
\end{tabular}

* For details of samples and their preparation, see p. $4 \mathrm{I} 4$.

Table 4. Comparison of 'chemically-available' iron as solubilized by gastric juice with in vivo absorption in man (Layrisse et al. 1969)

\begin{tabular}{|c|c|c|c|c|}
\hline Food* (dried) & $\begin{array}{l}\text { Present study } \\
\text { Total } \mu \mathrm{g} \mathrm{Fe} / \mathrm{g}\end{array}$ & $\begin{array}{l}\text { Layrisse et al. (1969) } \\
\text { Total } \mu \mathrm{g} \mathrm{Fe} / \mathrm{g}\end{array}$ & $\begin{array}{l}\text { Solubilization } \\
\text { (\% total) }\end{array}$ & $\begin{array}{l}\text { In vivo } \\
\text { absorption } \\
\text { (\% total) } \dagger\end{array}$ \\
\hline $\begin{array}{l}\text { Black beans } \\
\text { Fish }\end{array}$ & 76 & $85-90$ & 0.85 & 3.2 \\
\hline Mackerel & 43 & 一 & $4 \cdot 6$ & - \\
\hline $\left.\begin{array}{l}\text { Brycon whitei } \\
\text { Microptens salmonoides }\end{array}\right\}$ & - & I $I-17$ & - & $18 \cdot 3$ \\
\hline $\begin{array}{l}\text { Lettuce } \\
\text { Liver }\end{array}$ & 209 & $188-543$ & $4 \cdot 1$ & $5 \cdot 8$ \\
\hline$O x$ & 777 & - & 4.9 & - \\
\hline Veal & - & $163-407$ & - & $14 \cdot 5$ \\
\hline Maize flour & 25 & 21 & I. 4 & 5.9 \\
\hline Rice & II & 10 & 0.0 & 0.9 \\
\hline Soya-bean flour & 148 & $86-140$ & 10.8 & $17 \cdot 9$ \\
\hline Spinach $\ddagger$ & 377 & 77 & $10 \cdot 7$ & $t \cdot 7$ \\
\hline Veal muscle & $5 \mathrm{I}$ & $44-49$ & 6.6 & $20 \cdot 3$ \\
\hline Wheat & 49 & 85 & $4 \cdot 1$ & 7.9 \\
\hline
\end{tabular}

It is suggested that the Fe solubilized by gastric juice is available for absorption and an attempt was made to validate this suggestion by adding bran, oats and egg to the foods before incubating them with gastric juice. These foods reduce the amount of dietary Fe that is absorbed (Sharpe et al. 1950; Callender et al. 1970; Bjorn-Rasmussen, 1974). Table 3 shows the effect of mixing $0.1 \mathrm{~g}$ oats, bran or egg with $0.1 \mathrm{~g}$ of the food before incubating as described earlier. The sum of the Fe solubilized from the food alone and the bran, oats and egg alone provides the values for the calculated amount of Fe solubilized from the mixture. The results shown in Table 3 indicate that in all but two foods there was a substantial reduction in the amounts of Fe liberated. The two exceptions were lettuce and spinach and it is possible that residual ascorbic acid may have affected the results by chelating with 
Table 5. Iron solubilized from foods $(\%)$ by dilute hydrochloric acid $\left(p \mathrm{H}_{2} \cdot 5\right)$, gastric juice $(p H 2.5)$ or gastric juice $(p H 2.5)$ followed by adjustment of $p H$ to 7.5

\begin{tabular}{lccc}
\multicolumn{1}{c}{ Food } & $\begin{array}{c}c \\
\text { Dilute } \mathrm{HCl} \\
(\mathrm{pH} \mathrm{2.5)}\end{array}$ & $\mathrm{pH} \mathrm{2.5}$ & $\mathrm{pH} \mathrm{7.5}$ \\
Black beans & 2.4 & 0.9 & 0.0 \\
Fish & 2.8 & 4.6 & 0.0 \\
Lettuce & 4.0 & $4 . \mathrm{I}$ & 3.1 \\
Liver & 4.6 & 4.9 & 2.0 \\
Maize flour & 0.0 & 1.4 & 0.0 \\
Rice & 0.0 & 0.0 & 0.0 \\
Soya-bean flour & 23.9 & 10.9 & 8.1 \\
Spinach* & 10.4 & 10.7 & 10.3 \\
Veal muscle & 4.7 & 6.6 & 2.9 \\
Wheat & 3.7 & 4.1 & 0.0
\end{tabular}

* Omitted from statistical calculations, see Table 4.

Fe. Bran had no effect on the Fe solubilized from liver but oats substantially reduced the amount.

Another attempt to validate the findings was made by comparing the results with those reported on similar foods by Layrisse et al. (1969) for the absorption of Fe by human subjects. Such a comparison may be unreliable for two reasons. First the samples were not the same. For example, as shown in Table 4 the Fe content of some of the foods used by Layrisse et al. (1969) varied considerably (lettuce ranged from I 88 to $542 \mu \mathrm{g} \mathrm{Fe} / \mathrm{g}$ and soya-bean flour ranged from 86 to $\mathrm{I} 40 \mu \mathrm{g}$ ) and the foods used in the present work differed from these in the total $\mathrm{Fe}$ content. Additionally we used different types of fish and liver. However, it is possible that the chemical form of the Fe and hence the amounts solubilized and absorbed may be similar in foods of the same type.

Secondly, the present work is attempting to measure the Fe that is 'chemically available' whereas Layrisse et al. (1969) measured the amount absorbed, which would thus include the effects of other ingredients of the diet and also the nutritional status of the subjects.

With these limitations the results in Table 4 show a Pearson correlation coefficient of $0.82(P<0.01)$. The results for spinach were omitted since the sample used here contained five times as much Fe as that reported by Layrisse et al. (1969).

$\mathrm{Mg}-\mathrm{Mg}-\mathrm{Thwin}$ et al. (1975) suggested that available Fe could be measured by incubating the food with $\mathrm{HCl}$ or by a double incubation with pepsin- $\mathrm{HCl}$ followed by adjusting the $\mathrm{pH}$ to 7.5 to simulate the conditions in the duodenum.

Table 5 shows the effect of treating the foods with dilute $\mathrm{HCl}$ at $\mathrm{pH} 2.5$, with gastric juice at $\mathrm{pH} 2.5$ as used to obtain the results shown in Tables $\mathrm{l}$ and 2, and by incubating with gastric juice at $\mathrm{pH} 2.5$, then adjusting $\mathrm{pH}$ to 7.5 with $\mathrm{NaOH}$ and incubating again before centrifuging and measuring the Fe solubilized. Considerably less Fe was solubilized by the double incubation. $\mathrm{HCl}$ alone liberated more $\mathrm{Fe}$ than did the gastric juice for two foods, less from three foods and approximately the same amount for the remaining five foods.

When the results in Table 5 are compared with those of Layrisse et al. (1969) given in Table 4 for the proportion of food iron absorbed in vivo the following Pearson correlation coefficients were obtained: dilute $\mathrm{HCl}, r 0.52$, not significant; gastric juice at $\mathrm{pH} 2.5$, $r 0.82(P<0.01)$; double incubation with gastric juice at $\mathrm{pH} 2.5$ then adjusted to 7.5 , $r 0.5 \mathrm{I}$, not significant.

The effect of pepsin- $\mathrm{HCl}$ on the solubilization of $\mathrm{Fe}$ from soya-bean flour is shown in Fig. I and compared with the results of gastric juice at various levels of acidity. Both 


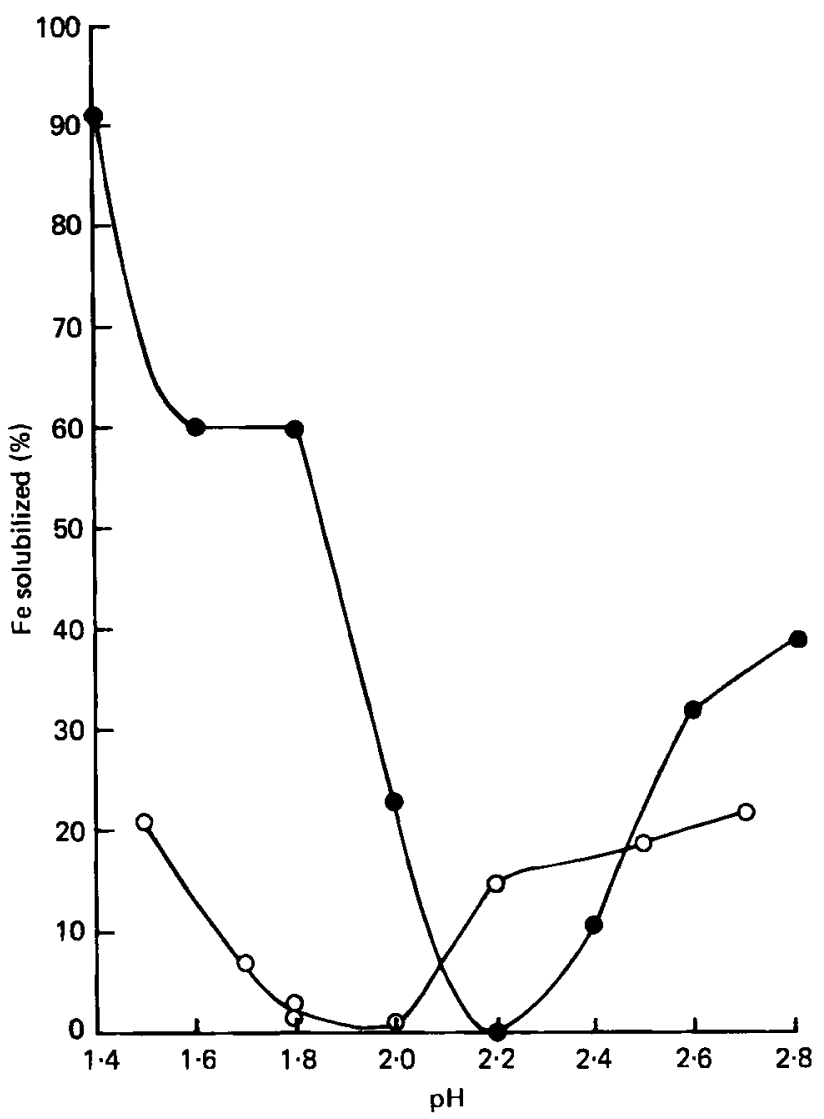

Fig. 1. Percentage of total iron solubilized from defatted raw soya-bean flour by pepsin $(5 \mathrm{~g} / \mathrm{l})$ hydrochloric acid (O_O ) and human gastric juice at various levels of acidity (adjusted with $\mathrm{HCl})(\mathrm{O} \longrightarrow \mathrm{O})$.

systems are $\mathrm{pH}$ dependent but the amount of $\mathrm{Fe}$ liberated from the soya-bean flour was very much greater with pepsin- $\mathrm{HCl}$ than that available to human subjects measured in vivo according to Layrisse et al. (1969). It would thus appear that the Fe liberated by the pepsin$\mathrm{HCl}$ system does not correspond to available $\mathrm{Fe}$.

\section{CONCLUSIONS}

It is stated in the Report on Recommended Daily Intakes (Department of Health \& Social Security, 1969) that the Committee considered whether it would be possible to express the $\mathrm{Fe}$ content of diets as 'Fe equivalents' using weighting factors based on the source of the $\mathrm{Fe}$, but at that time there was not enough information about the availability of $\mathrm{Fe}$ in different foods and in meals of different composition to justify such a procedure.

The method described here, namely the amount of Fe solubilized in vitro by human gastric juice, might serve such a purpose. The amount of Fe liberated from a food in the stomach might be that which is available for absorption, though the amount absorbed subsequently depends on the presence of other dietary factors as well as on the Fe status of the subject. If the Fe content of foods were expressed as 'available' Fe such a method would be similar to that adopted for vitamin A, in which the amount in the food is expressed as retinol equivalents. As is the situation with $\mathrm{Fe}$, vitamin $\mathrm{A}$ occurs in foods in different 
chemical forms that differ in their biological potency although the amount subsequently absorbed depends on the presence of other dietary factors such as vitamin $E$ and fats, and the conversion of carotene and transport in the blood depend also on the protein status of the subject. It is difficult to validate the in vitro method described here. The values differ from those given by in vitro methods previously suggested, such as solubility in $\mathrm{HCl}$ or in $\mathrm{HCl}$-pepsin (Jacobs \& Greenman, 1969) or after incubation in gastric juice at pH 2.5 then at 7.5 (Mg-Mg-Thwin et al. 1975), and also Narasinga Rao \& Prabhavathi (1978). The values correlate well with the accepted values for Fe absorption from a range of foods reported by Layrisse et al. (1969) although the latter values must include the effects of other dietary factors and the Fe status of the subjects as well as the availability of the $\mathrm{Fe}$ in the foods.

The difference between pepsin- $\mathrm{HCl}$ and gastric juice has not been explained and does not appear to be due to the proteins or the mucoproteins present in gastric juice.

There is some variability between results obtained on repeated samples of gastric juice from the same subject which appears to be pH-dependent and it may be necessary to standardize the $\mathrm{pH}$ to make the method reproducible. It will clearly be necessary to examine a much greater variety of foods under standardized conditions if the method is to be considered for use in standard food composition tables.

\section{REFERENCES}

Anson, M. L. (1938). J. Gen. Physiol. 22, 79.

Basson, W. D. \& Böhmer, R. G. (1972). Analyst, Lond. 97, 482.

Bjorn-Rasmussen, E. (1974). Nutr. Metab. 16, ror.

Callender, S. T., Marney, S. R. Jn \& Warner, G. T. (1970). Br. J. Haemat. I9, 657.

Davis, P. S., Multani, J. S., Cepurneek, C. P. \& Saltman, P. (1969). Biochem. Biophys. Res. Commun. 37, 532.

Department of Health and Social Security (1969). Recommended Intakes of Nutrients for the United Kingdom, no. I 20 London: HM Stationery Office.

Jacobs, A. \& Greenman, D. A. (1969). Br. med. J. 1, 673.

Kohler, G. O., Elvehjem, C. A. \& Hart, E. B. (1936). J. biol. Chem. r13, 49.

Layrisse, M., Cook, J. D., Martinez-Torres, C., Roche, M., Kuhn, I. N., Walker, R. B. \& Finch, C. A. (1969). Blood 33, 430.

Layrisse, M. \& Martinez-Torres, C. (1971). Prog. Haemat. 7, 137.

Mg-Mg-Thwin, Aung-Than-Batu \& Thein-Than (1975). Am. J. clin. Nutr. 28, 1350.

Narasinga Rao, B. S. \& Prabhavathi, T. (1978). Am. J. clin. Nutr. 31, 169.

Sanford, R. (1960). Nature, Lond. 185, 533 .

Sharpe, L. M., Peacock, W. C., Cooke, R. \& Harris, R. S. (1950). J. Nutr. 4I, 433. 